\title{
Role of Urodynamics in the Evaluation of Urinary Incontinence and Prolapse
}

\author{
Charles W. Nager
}

Published online: 13 June 2013

(C) Springer Science+Business Media New York 2013

\begin{abstract}
Urodynamics are functional tests of the bladder that are commonly requested for the evaluation of urinary incontinence and prolapse. As a diagnostic test that also can provide prognostic information, urodynamics should be requested when there is a specific question that needs to be answered. This chapter will review the literature that pertains to the common reasons for requesting urodynamics before stress urinary incontinence surgery and review recent randomized trials on urodynamic testing before stress incontinence surgery. In addition, the chapter will compare the predictive ability of urodynamic prolapse reduction stress testing with office-based prolapse reduction stress testing for detecting postoperative stress urinary incontinence in women without symptoms of stress urinary incontinence undergoing prolapse surgery.
\end{abstract}

Keywords Urodynamics $\cdot$ Stress urinary incontinence ·

Prolapsed $\cdot$ Urinary incontinence $\cdot$ Surgery

\section{Introduction}

Urodynamics are diagnostic tests that evaluate the function of the bladder. They often are used to help in the diagnosis of storage problems (e.g., incontinence) or for emptying problems (voiding dysfunction, obstruction). As with other diagnostic tests in medicine, especially invasive ones, they should be used after a history, physical, and office evaluation. Urodynamics should supplement the office evaluation and there should be a specific question that is being asked that will change management. The overall benefit of urodynamics

C. W. Nager $(\bowtie)$

UC San Diego Health System, 9350 Campus Point Dr, Suite 2A,

Mail Code 0974, La Jolla, CA 92037-1300, USA

e-mail: cnager@ucsd.edu is if it results in changes in diagnosis that result in changes in treatments that result in improvements in outcomes.

In a large health care claim study in the United States of more than 16,000 urodynamic studies, the most common clinical conditions at urodynamics were: 1) $34 \%$ stress urinary incontinence (SUI), 2) $16 \%$ urge urinary incontinence, 3) $12 \%$ urinary retention, 4) $9 \%$ pelvic organ prolapse, 5) $7 \%$ other urinary incontinence, 6) $7 \%$ mixed incontinence, and 7) $7 \%$ neurogenic bladder [1 0 . By far, the most controversial topics in urodynamics are whether they are needed before stress incontinence or prolapse surgery and this discussion will focus on the evidence for those topics.

\section{Urodynamics in the Evaluation of Stress Urinary Incontinence}

It is generally accepted that urodynamic studies are not needed before conservative, empiric, non-invasive treatments for stress urinary incontinence [2] or urinary incontinence in general. [3] However, several societies , such as the International Urogynecological Association and the International Consultation for Incontinence have recommended urodynamic studies before invasive treatments (i.e., surgery) for stress urinary incontinence $[4,5]$. On the other hand, the National Institute for Health and Clinical Excellence advised against routine urodynamic testing before surgery "in women with a clearly defined clinical diagnosis of pure stress urinary incontinence" [2]. Nevertheless, a survey in the United Kingdom found that $66 \%$ of specialists considered urodynamics essential in a clinical scenario of pure, demonstrable SUI [6]. In a Medicare claims analysis in the United States from 1999 to 2001, urodynamic studies were done within 6months preoperatively in $27 \%$ of women receiving a sling incontinence procedure [7]. 
Common reasons that are given for performing preoperative urodynamics include the following:

1. Confirming the diagnosis of stress urinary incontinence

2. Evaluation of urethral function

3. Evaluating for detrusor overactivity

4. Evaluating bladder emptying

For each of these reasons, there is an underlying assumption that these urodynamic findings would modify treatment and this modified treatment would improve outcomes. The purpose of this paper is to evaluate critically and to review these assumptions.

\section{Confirming the Diagnosis of Stress Urinary Incontinence}

Stress urinary incontinence (the sign) is the observation of involuntary leakage from the urethra, synchronous with exertion/effort, or sneezing or coughing, whereas urodynamic stress incontinence (USI) is noted during filling cystometry and is defined as the involuntary leakage of urine during increased abdominal pressure, in the absence of a detrusor contraction.

Insisting on USI (as opposed to just demonstrating the sign of SUI) before surgery would imply that USI is uncommon in the setting of demonstrable SUI and surgical outcomes would be better if USI was diagnosed. Recent literature suggests this is not the case. In a series of three large Urinary Incontinence Treatment Network (UITN) studies women with predominant SUI symptoms who demonstrated the sign of stress urinary incontinence (positive stress test) underwent preoperative urodynamic testing followed by the designated surgical intervention. The SISTeR (Stress Incontinence Surgical Treatment Efficacy Trial) was a randomized trial of 655 women who received either a Burch procedure or a pubovaginal sling [8]. The TOMUS (Trial Of MidUrethral Slings) was a randomized trial of 597 women who received either a retropubic or transobturator midurethral sling [9••]. The ValUE (Value of Urodynamic Evaluation) trial was a randomized trial of urodynamics before stress incontinence surgery of 630 women in which 315 received urodynamic testing $[10 \bullet \cdot]$. In all three studies, women had predominant SUI symptoms and demonstrated the sign of SUI on office evaluation with a positive stress test. The finding of USI was confirmed with urodynamic testing $89 \%$ of the time in the SISTEr trial [11], $86 \%$ in the TOMUS trial [9••], and $97 \%$ in the ValUE trial [10••]. Results are inconclusive for whether women with USI do better than women without USI. In the SISTEr trial, women with USI had better treatment outcomes [11] than women who only demonstrated the sign of SUI but did not have USI. However, in the more relevant trial of midurethral slings (TOMUS), which is the most common surgical treatment offered today, women with USI had worse treatment outcomes than women with the sign of SUI but without USI [12]. Therefore, when stress incontinence is the predominant complaint and it is demonstrable on office evaluation, urodynamic confirmation of this condition adds no apparent benefit to improving outcomes. Furthermore, in women with dominant stress symptoms and without prolapse who demonstrate stress incontinence on the office evaluation, this finding was confirmed urodynamically $97 \%$ of the time, suggesting the office evaluation is quite reliable in this group [10••]. The updated AUA Guidelines on the Surgical Management of Female Stress Urinary Incontinence reflect the importance of the stress test in the evaluation of the patient. The objective demonstration of SUI is considered a "standard," while urodynamics are only a "recommendation" as an additional diagnostic study that can be performed [13]. A negative stress test is considered an indication for further testing (i.e., urodynamics).

If USI is a preferable diagnosis to the clinical diagnosis of SUI, which is made by the sign of stress urinary incontinence, then the benefits of having a urethral catheter in place (as is done with urodynamic studies) should outweigh the disadvantages of a catheter in place. This is likely not the case. In one study more than $50 \%$ of women with SUI symptoms who did not demonstrate USI with the urethral catheter in place did so when it was removed [14]. This has led to an AUA/SUFU guideline statement that: "Clinicians should perform repeat stress testing with the urethral catheter removed in patients suspected of having SUI who do not demonstrate this finding with the catheter in place during urodynamic testing" [3]. It should be noted that a positive stress test after the urethral catheter is removed does not diagnose USI, but confirms SUI, and this recommendation further emphasizes the importance of a stress test in the evaluation of SUI even when urodynamics is being performed.

\section{Evaluation of Urethral Function}

Some investigators use results obtained from urethral function tests to predict failure or influence management (e.g., perform retropubic rather than transobturator slings in women with low urethral function tests). The two most commonly utilized urethral function tests are the Valsalva leak point pressure (VLPP), which indirectly measures urethral pressure by measuring the pressure in the abdomen or the bladder when leakage occurs, and the maximum urethral closure pressure (MUCP), which typically measures urethral function at rest but not during SUI conditions. In the 1990s, when urethral bulking injections were introduced, the concept of intrinsic sphincter deficiency (ISD) was developed in an attempt to clarify who should receive these bulking injections for stress incontinence. ISD originally meant severe incontinence, a poorly mobile urethra, and low MUCP or VLPP measures [15, 16]. More recent publications merely define ISD by the urodynamic measures and do not always 
specify if subjects with urethral mobility are excluded. This is important because poor urethral mobility is an independent risk factor for midurethral sling surgical failure [17]. Although not standardized, VLPP is commonly considered "low" if it is less than $50-90 \mathrm{~cm} \mathrm{H}_{2} \mathrm{O}$ [6], and an MUCP is considered low if it is less than 20-42 $\mathrm{cm} \mathrm{H}_{2} 0$ [6]. Markedly different MUCP values are obtained with different measuring technologies [18]. Receiver operator curve outcome data do not suggest there is a biological rationale for cut-off or threshold values for these measures [12]. A recent editorial titled "Intrinsic sphincter deficiency: what is it and does it matter anymore?" noted: "Even the most recent International Urogynecologic Association (IUGA)/International Continence Society (ICS) joint report on the terminology for female pelvic floor dysfunction ignores the diagnosis of ISD and the most recent International Consultation on Incontinence has omitted the definition of ISD for no longer being useful" [19].

Some physicians use urethral function measures to determine the route of midurethral sling, and Table 1 summarizes the randomized trial data on this subject. The UITN TOMUS study provides the best data on how different urethral function values may influence outcomes, because surgeons were blinded to the urodynamic results and therefore this eliminated surgeon modified changes based on UDS values. Even though MUCP and VLPP were poorly associated with severity [20], women with lower quartile MUCP or lower quartile VLPP values had twofold higher objective failure rates with either retropubic or transobturator midurethral slings than women with higher values for these measures [12]. However, the data from the TOMUS study do not suggest that VLPP measures should be used to determine the route of midurethral sling. Women with lower quartile VLPPs had group objective failure rates only $6 \%$ points lower (NS) with the transobturator approach than with the retropubic approach. Women with lower quartile MUCP's had group objective failure rates $13 \%$ points lower (NS) with the transobturator approach. The test for interaction did not suggest this was significant. No urodynamic measure was associated with subjective failure.

The best evidence for using urethral function tests to determine the route of midurethral sling comes from a randomized trial by Schierlitz et al. where women with ISD (either a MUCP $<20 \mathrm{~cm} \mathrm{H}_{2} \mathrm{O}$ or VLPP $<60 \mathrm{~cm} \mathrm{H}_{2} \mathrm{O}$ ) received either a retropubic or transobturator midurethral sling (Table 1) [21]. At 6 months, women who were randomized to the transobturator group had a $45 \%$ rate of urodynamic stress incontinence compared with a $21 \%$ rate in the retropubic group $(p=0.004)$. Thirteen percent of the women in the transobturator group requested repeat surgery, whereas none in the retropubic group did. There were marked improvements in both groups for pad test and patient reported quality of life outcomes and no between-group significant differences. The authors later reported a 3-year follow-up of this study in which $20 \%$ of the transobturator group underwent repeat surgery compared with $1.4 \%$ of the retropubic group [22]. Although repeat surgery is a very clinically relevant outcome measure, it is highly subject to physician biases and the potential bias in this study is that: 1) the physicians were not blinded to the initial surgical procedure; 2) they were already aware of their 6-month results suggesting that subjects with transobturator procedures were more likely to request repeat surgery; 3 ) and their salvage operation was a retropubic sling [23]. It is very likely that physicians would be more willing to perform a retropubic operation on someone who had a prior transobturator procedure than those who already had a retropubic sling.

If a surgeon's SUI surgery of choice is a retropubic midurethral sling, than urethral function studies do not provide information to change management. If a surgeon considers only subjective or patient centered quality of life outcomes as their primary outcome of concern, then neither the

Table 1 Results from retropubic vs. transobturator midurethral sling randomized trials grouped according to urethral function tests

\begin{tabular}{|c|c|c|c|c|c|}
\hline Reference & Group & Outcome & $\begin{array}{l}\text { Retropubic group } \\
\text { success }>\text { Transobturator } \\
\text { group success by x \% pts. }\end{array}$ & $P$ value & Comments \\
\hline \multirow{2}{*}{$\begin{array}{l}\text { TOMUS study } \\
\text { (Richter, NEJM, } \\
\text { 2010) [9••, 12] }\end{array}$} & \multirow[t]{2}{*}{ All } & Objective success & 3 & NS & \multirow[t]{2}{*}{ RCT of 597 subjects } \\
\hline & & Subjective success & 6 & NS & \\
\hline \multirow{2}{*}{$\begin{array}{l}\text { TOMUS study } \\
\text { (Nager, JU 2011) } \\
\text { [12] }\end{array}$} & Lower quartile VLPP & Objective success & 6 & NS & Surgeons blinded to UDS \\
\hline & Lower quartile MUCP & Objective success & 13 & NS & Trend almost significant \\
\hline $\begin{array}{l}\text { Schierlitz, OG, } \\
2008[21]\end{array}$ & $\begin{array}{l}\text { All subjects had } \\
\text { low MUCP or } \\
\text { low VLPP }\end{array}$ & $\begin{array}{l}\text { Postop USI at } \\
6 \text { months }\end{array}$ & $24 \%$ & 0.004 & $\begin{array}{l}\text { No difference in pad } \\
\text { weight, or QOL } \\
\text { measures } \\
\text { postoperatively }\end{array}$ \\
\hline $\begin{array}{l}\text { Schierlitz, OG, } \\
2012[22]\end{array}$ & & Need for Salvage TVT & $19 \%$ & $<0.001$ & $\begin{array}{l}\text { Surgeons and Evaluators } \\
\text { not blinded and aware } \\
\text { of earlier results }\end{array}$ \\
\hline
\end{tabular}


TOMUS nor the Schierlitz et al. studies suggest urethral function measures should be used to determine the route of surgery.

If physicians want to use MUCP or VLPP values to determine the route of surgery, does this justify this test in uncomplicated patients with no previous surgery? The UITN ValUE study provides some insight into this question. In this study of nearly 600 women with 53 different surgeons, women with no previous surgery, predominant stress symptoms, a positive stress test, a normal residual, and no prolapse were randomized to an office evaluation or an office evaluation and urodynamics. Ninety-three percent of subjects received a midurethral sling and $29 \%$ received a transobturator midurethral slings. The diagnosis of ISD was made in $13 \%$ of women after urodynamics. If you assume a $20 \%$-point group difference in objective failure between transobturator and retropubic midurethral slings, a $13 \%$ rate of ISD, and a transobturator sling rate of $29 \%$, then 133 UDS studies would be needed to prevent one objective failure.

\section{Evaluating for Detrusor Overactivity}

A commonly cited indication for preoperative urodynamic testing in women with SUI or mixed incontinence is to determine if there is detrusor overactivity (DO), and if so, alternative therapy could be initiated. It is well known that DO on filling cystometry is not a very sensitive finding and a clinical diagnosis of urge incontinence remains even in the absence of detrusor overactivity on urodynamic testing. However, if the diagnosis of DO is confirmed, the patients' management may change; surgery could be postponed or cancelled with priority given to treating the urge component first. Most studies suggest that women with urodynamic mixed incontinence do worse after surgical therapy than women with only urodynamic stress incontinence; the group difference often is small. In the SISTEr and TOMUS studies, women with predominant SUI symptoms and positive stress tests had a 9-14\% rate of DO on UDS and this group of women with DO had group treatment failure rates that were a nonsignificant 7-9\% points higher than the group without DO $[9 \cdot \bullet, 11]$.

It is not clear that in women with predominant and demonstrable SUI, surgery should be postponed until after a trial of medical therapy if DO is found on UDS. There are no definitive studies to clarify whether conservative or surgical therapy should be first-line therapy for women with mixed incontinence. In the ValUE study, detrusor overactivity was found in $10 \%$ of the subjects who had urodynamics, but management was rarely changed to nonsurgical therapy in this group [10••, 24]. In the Value of Urodynamics prior to Stress Incontinence Surgery (VUSIS) study, management was changed to conservative therapy in three women with DO, but there was no clinical improvement measured by the
Urogenital Distress Inventory UDI in the two women who never received surgical treatment $[25,26]$. It is not clear that the presence of DO should change management from a midurethral sling.

Mixed incontinence responds well to a midurethral sling. In a recent systematic review and meta-analysis on the effectiveness of midurethral slings in mixed urinary incontinence that included 13 studies, Jain et al. found that there were good cure rates $(85-97 \%)$ of the stress component and $30-85 \%$ cure rates for urge incontinence. There seemed to be no significant difference in the overall subjective and UUI cure between retropubic or transobturator routes [27•]. In summary, although subjects with detrusor overactivity on urodynamics may have slightly lower overall success rates than those without detrusor overactivity, there is not good evidence that a midurethral sling should not be performed, nor is there evidence that DO should dictate the type of MUS to perform.

\section{Evaluating Bladder Emptying}

The urodynamic studies of noninvasive uroflowmetry (NIF) or pressure flow studies (PFS) assess bladder emptying. Urodynamic bladder emptying studies are sometimes performed preoperatively in women with SUI with the rationale being that alternative management may be indicated or surgery could be done "looser" if voiding dysfunction is diagnosed. Earlier small studies suggested that straining was associated with failure after pubovaginal sling [28] and low peak flow rates were associated with delayed voiding after pubovaginal sling [29]. More recent studies have questioned these findings in women with normal postvoid residuals. In the UITN SISTEr study in which voiding dysfunction was defined as the need for surgical revision to improve voiding postoperatively or the need for catheterization due to voiding difficulties at any time beyond 6 weeks after surgery, 57 of 655 women met this definition. No preoperative urodynamic study findings were associated with an increased risk of voiding dysfunction in any group. Mean maximum flow during noninvasive flowmetry values were similar among women with voiding dysfunction compared with those without voiding dysfunction (23.4 vs. $25.7 \mathrm{ml}$ per second, $p=0.16$ ). Voiding pressures and degree of abdominal straining were not associated with postoperative voiding dysfunction. Voiding dysfunction rates at 6weeks in the TOMUS trial of midurethral slings were too low to permit meaningful analysis of preoperative urodynamic parameters and the prediction of voiding dysfunction $[9 \bullet \bullet$. However, urodynamic measures did not even predict the $24 \%$ of women who required a second voiding trial (Norton, Urology, in press). Similar lack of prediction of urodynamic values and postoperative voiding dysfunction were found in another large randomized trial of women who 
received either an inside-out or outside-in midurethral obturator sling [30]. Of the 224 women, 17 (7.6\%) had postoperative voiding dysfunction, defined as the need for postoperative catheterization. There were no differences in preoperative urodynamic parameters among those with or without voiding dysfunction. The various parameters that were evaluated included maximum flow (Qmax) $\leq 15 \mathrm{ml} / \mathrm{s}$, Qmax $<5^{\text {th }}$ percentile, average flow (Q avg) $\leq 10 \mathrm{ml} / \mathrm{s}, \mathrm{MUCP}<30 \mathrm{~cm}$ $\mathrm{H}_{2} \mathrm{O}$, detrusor pressure (Pdet) at Qmax, opening Pdet, functional urethral length (FUL), and post void residual (PVR). Therefore, in the most recent largest studies, preoperative urodynamic variables did not predict voiding dysfunction after pubovaginal slings, Burch procedures, or midurethral slings.

Randomized Trials of Urodynamic Testing before Stress Incontinence Surgery

A Cochrane review [31] and the National Institute for Health and Clinical Excellence [2] in the United Kingdom have recommended that randomized, controlled trials be performed to address the question of whether performing preoperative urodynamic studies improves outcomes. Two of these have now been completed with similar results suggesting urodynamic studies are not needed for the patient with uncomplicated stress incontinence.

The UITN ValUE study was a multicenter randomized, noninferiority trial of 630 women who were randomized to receive either a preoperative office evaluation or a preoperative office evaluation and urodynamic testing [10••]. The primary outcome was treatment success at 12 months, defined as a reduction in the score on the Urogenital Distress Inventory [25] of $70 \%$ or more and a response of "much better" or "very much better" on a Patient Global Impression of Improvement [32]. Important inclusion criteria included a score on the Medical, Epidemiological, and Social Aspects of Aging (MESA) questionnaire [33] for stress urinary incontinence that was greater than the score on this questionnaire for urgency incontinence, a postvoid residual urine volume of less than $150 \mathrm{ml}$, a negative urinalysis or urine culture, a clinical assessment of urethral mobility, a desire for surgery for stress urinary incontinence, and a positive provocative stress test (defined as an observed transurethral loss of urine that was simultaneous with a cough or Valsalva maneuver at any bladder volume). Important exclusion criteria were previous surgery for incontinence, and anterior or apical pelvic-organ prolapse of $1 \mathrm{~cm}$ or more distal to the hymen. At 11 sites, with 53 participating surgeons, 630 women were randomized (315 in each group). The rate of treatment success was essentially the same in each group (Table 2): $76.9 \%$ (203/264 women) in the urodynamictesting group compared with $77.2 \%(200 / 259)$ in the evaluation-only group. No significant differences were found between the urodynamic-testing and evaluation-only groups for several secondary outcome measures either. The results suggested that urodynamic testing rarely changed the primary diagnosis of stress urinary incontinence, often changed the secondary diagnosis [24], increased physician confidence in the office diagnosis (Zimmern, Urology, in press), rarely changed management and did not change outcomes. The investigators found that preoperative office evaluation alone was not inferior to office evaluation and urodynamic testing for outcomes at 1 year in women with demonstrable stress urinary incontinence and concluded that these results argue against routine preoperative urodynamic testing in patients with uncomplicated stress urinary incontinence $[10 \bullet \cdot]$.

The Value of Urodynamics prior to Stress Incontinence Surgery (VUSIS) trial was a multicenter noninferiority, randomized, controlled trial of a similar patient group in the Netherlands with a slightly different design and the results complement the ValUE study [34]. A total of 578 participants underwent urodynamics and 268 women with discordant findings were approached for consent; 126 agreed and were randomized to immediate surgery $(n=64)$ or individually tailored therapy $(n=62)$. The mean improvement in the Urogenital Distress Inventory was 44 points for immediate surgery and 39 points for the individually tailored group. The authors concluded that an immediate midurethral sling procedure is not inferior to an individually tailored treatment based on urodynamic findings.

\section{Urodynamics in the Evaluation of Prolapse}

Pelvic organ prolapse is the fourth most common indication for urodynamic testing [1•]. Urodynamics are sometimes requested before prolapse surgery in an attempt to answer whether the patient has occult stress incontinence, and if so, presumably would undergo an incontinence operation at the same time as their prolapse surgery. This question is complicated because some investigators favor a staged approach even if stress incontinence symptoms are present and demonstrated,
Table 2 Treatment success rates in the ValUE trial $[10 \bullet \bullet]$

\begin{tabular}{llll}
\hline $\begin{array}{l}\text { Office evaluation only } \\
\text { group }\end{array}$ & $\begin{array}{l}\text { Urodynamic testing } \\
\text { group }\end{array}$ & $\begin{array}{l}\text { Difference } \\
\text { (confidence interval) }\end{array}$ & Interpretation \\
\hline $77.2 \%(200 / 259)$ & $76.9 \%(203 / 264)$ & $0.3 \%(-7.5 \%$ to $6.9 \%)$ & $\begin{array}{l}\text { Office evaluation is noninferior } \\
\text { to urodynamic testing }\end{array}$ \\
\hline
\end{tabular}


Table 3 Results from two randomized trials in women without symptoms of stress urinary incontinence who had a prolapse operation with or without an incontinence operation grouped according to the results of prolapse reduction stress testing

\begin{tabular}{|c|c|c|c|c|c|c|}
\hline & \multirow{2}{*}{$\begin{array}{l}\text { Prolapse reduction Stress } \\
\text { Test (PRST) Group }\end{array}$} & \multicolumn{2}{|c|}{ Postoperative incontinence rates } & \multirow{2}{*}{$\begin{array}{l}\text { Odds ratio } \\
(95 \% \mathrm{CI})\end{array}$} & \multirow[t]{2}{*}{ NNT (95 \% CI) } & \multirow[t]{2}{*}{$p$ valu } \\
\hline & & $\begin{array}{l}\text { Prolapse } \\
\text { Surgery+Burch } \\
\text { or TVT }\end{array}$ & $\begin{array}{l}\text { Prolapse } \\
\text { Surgery+Sham }\end{array}$ & & & \\
\hline \multirow{3}{*}{$\begin{array}{l}\text { CARE Trial }[36,37] \\
\text { Sacrocolpopexy } \pm \text { Burch } \\
\text { procedure }\end{array}$} & All $(n=322)$ & $23.8 \%(35 / 147)$ & $44.1 \%(67 / 152)$ & $2.52(1.54,4.14)$ & $5.4(3.3,10.2)$ & $<0.001$ \\
\hline & Positive UDS PRST $(n=78)$ & $32 \%(12 / 38)$ & $58 \%(23 / 40)$ & $2.93(1.16,7.41)$ & $3.8(2.1,21.6)$ & 0.023 \\
\hline & Negative UDS PRST $(n=215)$ & $20.8 \%(22 / 106)$ & $38.2 \%(41 / 109)$ & $2.30(1.25,4.23)$ & $5.7(3.5,20.3)$ & 0.007 \\
\hline \multirow{3}{*}{$\begin{array}{l}\text { OPUS Trial }[35 \bullet, 38] \text { Vaginal } \\
\text { Prolapse Repair } \pm \text { TVT }\end{array}$} & All $(n=337)$ & $23.6 \%(39 / 165)$ & $49.4 \%(85 / 172)$ & $3.22(2.0,5.26)$ & $3.9(2.8,6.5)$ & $<0.001$ \\
\hline & Positive Office PRST $(n=111)$ & $29.6 \%(16 / 54)$ & $71.9 \%(41 / 57)$ & $7.77(2.95,20.44)$ & $2.4(1.6,4.2)$ & $<0.001$ \\
\hline & Negative Office PRST $(n=220)$ & $20.6 \%(22 / 107)$ & $38.1 \%(43 / 113)$ & $2.49(1.33,4.65)$ & $5.7(3.4,18.4)$ & 0.004 \\
\hline
\end{tabular}

whereas there is some evidence that an incontinence operation may even benefit women without symptoms of incontinence and with negative prolapse reduction stress tests $[35 \bullet \cdot, 36]$.

In the CARE study, patients with prolapse but without complaints of incontinence underwent a sacrocolpopexy and were randomized to a Burch procedure or not. They underwent preoperative urodynamic prolapse reduction stress testing by a variety of methods [37]. In the OPUS trial, patients with prolapse but without complaints of incontinence underwent a vaginal prolapse repair and were randomized to TVT retropubic midurethral sling or not [35••]. In the OPUS study, subjects had a standardized preoperative office prolapse reduction stress test with a $300-\mathrm{ml}$ fill, catheter removal, and prolapse reduction with a Proctoswab(s) in supine and, if needed, standing positions. Table 3 demonstrates the postoperative incontinence rates for the entire group of CARE (Row 1) and OPUS participants (Row 4) but also demonstrates the results in the subgroups with positive (Rows $2 \& 5$ ) and negative (Rows $3 \& 6$ ) prolapse reduction stress tests $[32,35 \bullet \cdot, 36,38]$. Women with positive prolapse reduction stress tests benefitted the most from an incontinence procedure at the time of prolapse surgery in each of these studies. In each study, the group with the lowest number to treat to prevent one case of postoperative stress incontinence was in the group with the positive preoperative prolapse reduction stress test. There is no evidence to suggest that urodynamic prolapse reduction stress testing results in better predictive value than office based prolapse reduction stress testing. In my practice, I evaluate prolapse patients with an office prolapse reduction stress test and use that information to counsel patients and make recommendations to perform a midurethral sling at the time of vaginal prolapse repair if the prolapse reduction stress test is positive. If the prolapse reduction stress test is negative, I explain that postoperative stress incontinence is still possible, but unlikely, and I recommend a wait and see and possible staged procedure if bothersome stress incontinence develops after the vaginal prolapse surgery.
Urodynamics to assess voiding function in the presence of prolapse also is complicated, because advanced apical or anterior prolapse impairs bladder emptying, and these patients may have to reduce manually their prolapse to void, have elevated post void residuals, or evidence of obstructed voiding during urodynamics. Currently, there is no standard method of prolapse reduction during the voiding phase, nor is there evidence to suggest that obstructed voiding due to prolapse should modify prolapse surgery techniques. Urodynamics may show the absence of detrusor function during voiding; this finding may be helpful in counseling subjects with advanced prolapse and urinary retention; namely, they may not fully recover voiding function after prolapse repair.

\section{Conclusions}

Although stress urinary incontinence is the most common indication for urodynamic testing, there are two recent, noninferiority, randomized trials demonstrating that urodynamic testing is not needed for low-risk women with uncomplicated stress incontinence. These are women who present with no previous surgery, predominant stress symptoms, a positive stress test, a normal residual, and no prolapse. No randomized trials have evaluated preoperative urodynamics in more complicated patients, but urodynamic testing can provide helpful information about bladder function and may be indicated in the setting of diagnostic uncertainty, treatment plan difficulty, failed treatment, combined storage and emptying disorders, voiding dysfunction, neurological disease, uncertainty about the relative contribution of urge and stress components, or suspected poor urethral function. Although urodynamics also are performed commonly for pelvic organ prolapse, the information that it provides for the presence of occult stress incontinence may be as readily obtained with an office prolapse reduction stress test. 


\section{Compliance with Ethics Guidelines}

Conflict of Interest Charles W. Nager received honoraria for an UpToDate educational program.

Human and Animal Rights and Informed Consent This article does not contain any studies with human or animal subjects performed by any of the authors.

\section{References}

Papers of particular interest, published recently, have been highlighted as:

- Of importance

-• Of major importance

1. - Reynolds WS, et al. Patterns and predictors of urodynamics use in the United States. J Urol. 2012. A good reference article for indications of urodynamics in the United States.

2. NICE. Urinary incontinence. The management of urinary incontinence in women National Institue for Health and Clinical Excellence (NICE), 2006. NICE clinical guideline 40: p. 1-36.

3. Winters JC et al. Urodynamic studies in adults: AUA/SUFU guideline. J Urol. 2012;188(6 Suppl):2464-72.

4. Ghoniem $\mathrm{G}$ et al. Evaluation and outcome measures in the treatment of female urinary stress incontinence: International Urogynecological Association (IUGA) guidelines for research and clinical practice. Int Urogynecol J Pelvic Floor Dysfunct. 2008;19(1):5-33.

5. Abrams $\mathrm{P}$ et al. Fourth International Consultation on Incontinence Recommendations of the International Scientific Committee: Evaluation and treatment of urinary incontinence, pelvic organ prolapse, and fecal incontinence. Neurourol Urodyn. 2010;29(1):213-40.

6. Hilton $\mathrm{P}$ et al. Assessing professional equipoise and views about a future clinical trial of invasive urodynamics prior to surgery for stress urinary incontinence in women: a survey within a mixed methods feasibility study. Neurourol Urodyn. 2012;31(8):1223-30.

7. Anger JT et al. The role of preoperative testing on outcomes after sling surgery for stress urinary incontinence. J Urol. 2007;178(4 Pt 1):1364-8. discussion 1368-9.

8. Albo ME et al. Burch colposuspension versus fascial sling to reduce urinary stress incontinence. N Engl J Med. 2007;356(21):2143-55.

9. •• Richter HE et al. Retropubic versus transobturator midurethral slings for stress incontinence. N Engl J Med. 2010;362(22):2066-76. A large, multicenter, randomized trial from the Urinary Incontinence Network comparing retropubic and transobturator approaches for midurethral slings showing they are similar.

10. $\bullet$ Nager $\mathrm{CW}$ et al. A randomized trial of urodynamic testing before stress-incontinence surgery. N Engl J Med. 2012;366(21):1987-97. A large, multicenter, randomized trial from the Urinary Incontinence Network demonstrating outcomes are simlar after office evaluation or office and urodynamic evalaution for women with uncomplicated stress urinary incontinence.

11. Nager $\mathrm{CW}$ et al. Urodynamic measures do not predict stress continence outcomes after surgery for stress urinary incontinence in selected women. J Urol. 2008;179(4):1470-4.

12. Nager $\mathrm{CW}$ et al. Baseline urodynamic predictors of treatment failure 1 year after mid urethral sling surgery. J Urol. 2011;186(2):597-603.

13. Dmochowski RR et al. Update of AUA guideline on the surgical management of female stress urinary incontinence. J Urol. 2010;183(5):1906-14.
14. Maniam P, Goldman HB. Removal of transurethral catheter during urodynamics may unmask stress urinary incontinence. J Urol. 2002;167(5):2080-2.

15. Bump RC et al. Diagnosing intrinsic sphincteric deficiency: comparing urethral closure pressure, urethral axis, and Valsalva leak point pressures. Am J Obstet Gynecol. 1997;177(2):303-10.

16. Fantl JA, Newman D., Colling J, DeLancey JOL, Keeys C, Loughery R, McDowell BJ, Norton P, Ouslander J, Schnelle J, Staskin D, Tries J, Urich V, Vitousek SH, Weiss BD, Whitmore K., Managing Acute and chronic urinary incontinence. Clinical Practice Guideline: Quick Reference Guide for Clinicians, No. 2, 1996 Update. 1996, U.S. Department of Health and Human Services, Public Health Service, Agency for Health Care Policy and Research: Rockville, MD.

17. Richter HE et al. Demographic and clinical predictors of treatment failure one year after midurethral sling surgery. Obstet Gynecol. 2011;117(4):913-21.

18. Wang AC, Chen MC. A comparison of urethral pressure profilometry using microtip and double-lumen perfusion catheters in women with genuine stress incontinence. BJOG. 2002;109(3):322-6.

19. Swift S. Intrinsic sphincter deficiency: what is it and does it matter anymore? Int Urogynecol J, 2012.

20. Nager $\mathrm{CW}$ et al. Urodynamics, the supine empty bladder stress test, and incontinence severity. Neurourol Urodyn. 2010;29(7):130611.

21. Schierlitz L et al. Effectiveness of tension-free vaginal tape compared with transobturator tape in women with stress urinary incontinence and intrinsic sphincter deficiency: a randomized controlled trial. Obstet Gynecol. 2008;112(6):1253-61.

22. Schierlitz $\mathrm{L}$ et al. Three-year follow-up of tension-free vaginal tape compared with transobturator tape in women with stress urinary incontinence and intrinsic sphincter deficiency. Obstet Gynecol. 2012;119(2 Pt 1):321-7.

23. Stav K et al. Repeat synthetic mid urethral sling procedure for women with recurrent stress urinary incontinence. J Urol. 2010;183(1):241-6.

24. Sirls LT et al. The effect of urodynamic testing on clinical diagnosis, treatment plan and outcomes in women undergoing stress urinary incontinence surgery. J Urol. 2013;189(1):204-9.

25. Shumaker SA et al. Health-related quality of life measures for women with urinary incontinence: the Incontinence Impact Questionnaire and the Urogenital Distress Inventory. Continence Program in Women (CPW) Research Group. Qual Life Res. 1994;3(5):291306.

26. van Leijsen SA et al. Can preoperative urodynamic investigation be omitted in women with stress urinary incontinence? A non-inferiority randomized controlled trial. Neurourol Urodyn. 2012;31(7):111823.

27. - Jain $P$ et al. Effectiveness of midurethral slings in mixed urinary incontinence: a systematic review and meta-analysis. Int Urogynecol J. 2011;22(8):923-32. A very good review of midurethral slings showing comparable effectiveness of the two approaches for this population.

28. Iglesia $\mathrm{CB}$ et al. Effect of preoperative voiding mechanism on success rate of autologous rectus fascia suburethral sling procedure. Obstet Gynecol. 1998;91(4):577-81.

29. McLennan MT, Melick CF, Bent AE. Clinical and urodynamic predictors of delayed voiding after fascia lata suburethral sling. Obstet Gynecol. 1998;92(4 Pt 1):608-12.

30. Mostafa A, Madhuvrata P, Abdel-Fattah M. Preoperative urodynamic predictors of short-term voiding dysfunction following a transobturator tension-free vaginal tape procedure. Int J Gynaecol Obstet. 2011;115(1):49-52.

31. C Schmid, C.M., B Feiner, K Baessler, C Glazener 2012 Cochrane Review: Surgical Management of Pelvic Organ Prolapse in 37th Annual IUGA Meeting. 2012. Brisbane, Australia: International Urogynecology Journal (2012) 23 ( Suppl 2). 
32. Yalcin I, Bump RC. Validation of two global impression questionnaires for incontinence. Am J Obstet Gynecol. 2003;189(1):98-101.

33. Herzog AR et al. Two-year incidence, remission, and change patterns of urinary incontinence in noninstitutionalized older adults. J Gerontol. 1990;45(2):M67-74.

34. van Leijsen SA et al. Value of urodynamics before stress urinary incontinence surgery: a randomized controlled trial. Obstet Gynecol. 2013;121(5):999-1008.

35. •- Wei JT et al. A midurethral sling to reduce incontinence after vaginal prolapse repair. N Engl J Med. 2012;366(25):2358-67. A large, multicenter, randomized trial from the Pelvic Floor Disorders Network evaluating the addition of a TVT to subjects without incontinence undergoing vaginal prolapse surgery.
36. Brubaker L et al. Abdominal sacrocolpopexy with Burch colposuspension to reduce urinary stress incontinence. N Engl J Med. 2006;354(15):1557-66.

37. Visco AG et al. The role of preoperative urodynamic testing in stresscontinent women undergoing sacrocolpopexy: the Colpopexy and Urinary Reduction Efforts (CARE) randomized surgical trial. Int Urogynecol J Pelvic Floor Dysfunct. 2008;19(5):60714.

38. Nager CW. The value of the preoperative prolapse reduction stress test in women without stress incontinence symptoms undergoing vaginal prolapse surgery with or without a TVT: results from the OPUS trial. Female Pelvic Medicine \& Reconstructive Surgery, 2011. 17(5, Supplement 2). 